\title{
A Global Convergence Algorithm for the Supply Chain Network Equilibrium Model
}

\author{
Lei Wang \\ Feixian School \\ Linyi University \\ Feixian, Shandong, P.R. China.
}

\begin{abstract}
In this paper, we first present an auxiliary problem method for solving the generalized variational inequalities problem on the supply chain network equilibrium model (GVIP), then its global convergence is also established under milder conditions.
\end{abstract}

Keywords- Supply chain management; network equilibrium model; generalized variational inequalities; algorithm; globally convergent.

\section{INTRODUCTION}

The topics of supply chain model, analysis, computation, and management are of great interests, both from practical and research perspectives. Research in this area is interdisciplinary by nature since it involves manufacturing, transportation, logistics, and retailing/marketing. A lot of literatures have paid much attention to this area. The interested readers may consult the recent survey papers by Stadtler and Kilger, Poirier, Giannessi and Maugeri (Refs.[1-4]) and references therein. For example, Nagurney et al. ([5]) developed a variational inequality based supply chain network equilibrium model consisting of three tiers of decision-makers in the network. They established some governing equilibrium conditions based on the optimality conditions of the decision-makers along with the market equilibrium conditions in 2002. In 2004, Dong et al.([6]) establish the finite-dimensional variational inequality formulation for a supply chain network model consisting of manufacturers and retailers in which the demands associated with the retail outlets are random.

In 2005, Nagurney et al. ([7]) establish the finitedimensional variational inequality formulation for a supply chain network model in which both physical and electronic transactions are allowed and in which supply side risks as well as demand side risk are included in the formulation. The model consists of three tiers of decision-makers: the manufacturers, the distributors, and the retailers, with the demands associated with the retail outlets being random. In recent years, variational inequalities have been extended in many directions via innovative techniques to study a wide class of problem arising in pure and applied sciences. A useful and important generalization is called the general variational inequality problem (GVIP). This problem was introduced first by Noor([8]) in 1988, it and related problems have been studied by many researchers(See Refs.[4-15])
In this paper, we consider the solution method for GVIP on supply chain network equilibrium model of finding $x^{*}$ in $R^{n}$ such that

$$
\left\langle F(x)-F\left(x^{*}\right), G\left(x^{*}\right)\right\rangle \geq 0, \forall F(x) \in \Omega, x \in R^{n},
$$

where $R^{n}$ be a real Euclidean space, whose inner product and the Euclidean 2-norm are denoted by $\langle\cdot, \cdot\rangle$ and $\|\cdot\|$, respectively. Let $\Omega$ be a nonempty closed convex set in $R^{n}$. Given nonlinear mappings $G: R^{n} \rightarrow R^{m}, F(x)=M x+p$ , $M \in R^{m \times n}, \quad p \in R^{m}$, and $F$ is onto $\Omega$. The solution set of the GVIP is denoted by $X^{*}$ which is always assumed to be nonempty.

In recent years, many methods have been proposed to solve the GVIP, among various of efficient methods for solving GVIP, projection method is the simplest one([10-15]). Solodov and Svaiter ([11]), He ([10]), Wang ([15]) applied a new class of projection-contraction (PC) methods to monotone GVIP. Different from the algorithm above, we proposed a new method for solving the GVIP under milder conditions, a strictly convex quadratic programming only need to be solved at each iteration.

\section{Algorithm AND CONVERGENCE}

In this section, we give a new-type method to solve the GVIP under milder conditions. We first need the definition of projection operator and some relate properties ([16]).

For nonempty closed convex set $\Omega \subset R^{n}$ and any vector $x \in R^{n}$, the orthogonal projection of $x$ onto $\Omega$, i.e., $\operatorname{argmin}\{\|y-x\| \mid y \in \Omega\}$, is denoted by $P_{\Omega}(x)$. For (1), $\rho>0$ is given a constant,

$$
e(x):=F(x)-P_{\Omega}[F(x)-\rho G(x)]
$$

is called projection-type residual function, and let $r(x):=\|e(x)\|$. The following conclusion provides the relationship between the solution set of (1) and that of projection-type residual function which is due to Noor([8]). 
Lemma 2.1 $x$ is a solution of (1) if and only if $r(x)=0$.

To establish the following algorithm, we also need the following conclusion in [17].

Lemma 2.2 Suppose that the non-homogeneous linear equation system $H y=b$ is consistent. Then $y=H^{+} b$ is the solution with the minimum 2-norm, where $\mathrm{H}^{+}$is the pesudoinverse of $H$.

In this following, we give a description of our proposed algorithm.

\section{Algorithm 2.1}

Step1. Take $\varepsilon>0$, parameters $0<\rho<2 \mu$, and initial point $x^{0} \in R^{n}$. Set $k \stackrel{\mathrm{v}}{=0}$;

Step2. Compute $F\left(x^{k+1}\right)$ by solving the following problem

$$
\begin{gathered}
\min \quad\left(F(x)-F\left(x^{k}\right)\right)^{\cdot}\left(F(x)-F\left(x^{k}\right)\right) \\
+2 \rho\left(F(x)-F\left(x^{k}\right)\right)^{\cdot} G\left(x^{k}\right)
\end{gathered}
$$

s.t.

$$
F(x) \in \Omega \text {; }
$$

Step3. If $\left\|F\left(x^{k+1}\right)-F\left(x^{k}\right)\right\| \leq \varepsilon$ go to Step 4, otherwise, go to Step 2 with $k=k+1$;

Step4. Let $x^{k+1}=M^{+}\left(F\left(x^{k+1}\right)-p\right)$, where $M^{+}$is the pseudo inverse of $M$. Stop.

By the definition of projection operator, we can easily get that $F\left(x^{k+1}\right)$ is a solution of problem (2) if and only if

$$
F\left(x^{k+1}\right)=P_{\Omega}\left(F\left(x^{k}\right)-\rho G\left(x^{k}\right)\right) .
$$

To establish the global convergence of Algorithm 2.1, we will state the following some well-known definitions ([18]).

Definition 2.1 The mapping $G: R^{n} \rightarrow R^{m}$ is said to be strongly pseudo monotone with respect to $F$ if there is constant $\mu>0$ such that

$$
\begin{gathered}
\langle G(y), F(x)-F(y)\rangle \geq 0 \\
\Rightarrow\langle G(x), F(x)-F(y)\rangle \geq \mu\|G(x)-G(y)\|^{2}, \\
\forall x, y \in R^{n} .
\end{gathered}
$$

Obviously, If the mapping $G$ is strongly monotone with respect to $F$ ([18]), then The mapping $G$ is strongly pseudo monotone with respect to $F$, but the converse is not true in general. For example, $G(x)=2-x, F(x)=x$, the mapping $G$ is strongly pseudo monotone with respect to $F$ with constant 1 in interval $[0,1]$, but it is not strongly monotone and even not monotone.
Theorem 2.1 Suppose that the mapping $G$ is strongly pseudo monotone with respect to $F$, then the sequence $\left\{x^{k}\right\}$ globally converges to a solution of the GVIP.

Proof: Since $\rho>0$, (2) has an unique solution, denoted by $F\left(x^{k+1}\right)$. Obviously, if $F\left(x^{k+1}\right)=F\left(x^{k}\right)$, i.e.,

$$
r\left(x^{k}\right)=F\left(x^{k}\right)-P_{\Omega}\left(F\left(x^{k}\right)-\rho G\left(x^{k}\right)\right)=0,
$$

using Lemma 2.1, then $x^{k}$ is a solution of GVIP.

In the following analysis, we assume that Algorithm 2.1 generates an infinite sequence. Suppose that $F\left(x^{k+1}\right) \neq F\left(x^{k}\right)$ holds, and the objective function of (2) is denoted by $H(x)$ with $x^{k}=x^{*}\left(x^{*} \in X^{*}\right)$. We would prove that the sequence $\left\{H\left(x^{k}\right)\right\}$ is monotone decreasing. To this end, we set

$$
\begin{aligned}
& \Psi(k, k+1)=H\left(x^{k}\right)-H\left(x^{k+1}\right) \\
& =\left(F\left(x^{k}\right)-F\left(x^{*}\right)\right)^{\cdot}\left(F\left(x^{k}\right)-F\left(x^{*}\right)\right) \\
& +2 \rho\left\langle G\left(x^{*}\right), F\left(x^{k}\right)-F\left(x^{*}\right)\right\rangle \\
& -\left(F\left(x^{k+1}\right)-F\left(x^{*}\right)\right)^{\bullet}\left(F\left(x^{k+1}\right)-F\left(x^{*}\right)\right) \\
& -2 \rho\left\langle G\left(x^{*}\right), F\left(x^{k+1}\right)-F\left(x^{*}\right)\right\rangle \\
& =\left(F\left(x^{k}\right)\right)^{\bullet} F\left(x^{k}\right)-\left(F\left(x^{*}\right)\right)^{\bullet} F\left(x^{*}\right) \\
& -2\left\langle F\left(x^{*}\right), F\left(x^{k}\right)-F\left(x^{*}\right)\right\rangle \\
& -\left(F\left(x^{k+1}\right)\right)^{\bullet} F\left(x^{k+1}\right)+\left(F\left(x^{*}\right)\right)^{\bullet} F\left(x^{*}\right) \\
& +2\left\langle F\left(x^{*}\right), F\left(x^{k+1}\right)-F\left(x^{*}\right)\right\rangle \\
& +2 \rho\left\langle G\left(x^{*}\right), F\left(x^{k}\right)-F\left(x^{k+1}\right)\right\rangle \\
& =\left(F\left(x^{k}\right)\right)^{\bullet} F\left(x^{k}\right)-\left(F\left(x^{k+1}\right)\right)^{\bullet} F\left(x^{k+1}\right) \\
& +2\left\langle F\left(x^{*}\right), F\left(x^{k+1}\right)-F\left(x^{k}\right)\right\rangle \\
& +2 \rho\left\langle G\left(x^{*}\right), F\left(x^{k}\right)-F\left(x^{k+1}\right)\right\rangle \\
& =\left(F\left(x^{k}\right)\right)^{\bullet} F\left(x^{k}\right)-\left(F\left(x^{k+1}\right)\right)^{\bullet} F\left(x^{k+1}\right) \\
& -2\left\langle F\left(x^{k+1}\right), F\left(x^{k}\right)-F\left(x^{k+1}\right)\right\rangle \\
& +2\left\langle F\left(x^{k+1}\right)-F\left(x^{*}\right), F\left(x^{k}\right)-F\left(x^{k+1}\right)\right\rangle \\
& +2 \rho\left\langle G\left(x^{*}\right), F\left(x^{k}\right)-F\left(x^{k+1}\right)\right\rangle \\
& =\left(F\left(x^{k}\right)-F\left(x^{k+1}\right)\right)^{\cdot}\left(F\left(x^{k}\right)-F\left(x^{k+1}\right)\right) \\
& +2\left\langle F\left(x^{k+1}\right)-F\left(x^{k}\right), F\left(x^{*}\right)-F\left(x^{k+1}\right)\right\rangle \\
& +2 \rho\left\langle G\left(x^{*}\right), F\left(x^{k}\right)-F\left(x^{k+1}\right)\right\rangle
\end{aligned}
$$




$$
\begin{aligned}
& \geq\left(F\left(x^{k}\right)-F\left(x^{k+1}\right)\right)^{\cdot}\left(F\left(x^{k}\right)-F\left(x^{k+1}\right)\right) \\
& -2 \rho\left\langle G\left(x^{k}\right), F\left(x^{*}\right)-F\left(x^{k+1}\right)\right\rangle \\
& +2 \rho\left\langle G\left(x^{*}\right), F\left(x^{k}\right)-F\left(x^{k+1}\right)\right\rangle \\
& =\left(F\left(x^{k}\right)-F\left(x^{k+1}\right)\right)^{\bullet}\left(F\left(x^{k}\right)-F\left(x^{k+1}\right)\right) \\
& +2 \rho\left\langle G\left(x^{k}\right), F\left(x^{k}\right)-F\left(x^{*}\right)\right\rangle \\
& -2 \rho\left\langle G\left(x^{k}\right), F\left(x^{k}\right)-F\left(x^{k+1}\right)\right\rangle \\
& +2 \rho\left\langle G\left(x^{*}\right), F\left(x^{k}\right)-F\left(x^{k+1}\right)\right\rangle \\
& \geq\left(F\left(x^{k}\right)-F\left(x^{k+1}\right)\right)^{\bullet}\left(F\left(x^{k}\right)-F\left(x^{k+1}\right)\right) \\
& +2 \rho \mu\left\|G\left(x^{k}\right)-G\left(x^{*}\right)\right\|^{2} \\
& -2 \rho\left\langle G\left(x^{k}\right)-G\left(x^{*}\right), F\left(x^{k}\right)-F\left(x^{k+1}\right)\right\rangle \\
& \geq\left\|F\left(x^{k}\right)-F\left(x^{k+1}\right)\right\|^{2}+2 \rho \mu\left\|G\left(x^{k}\right)-G\left(x^{*}\right)\right\|^{2} \\
& -2 \rho\left\|G\left(x^{k}\right)-G\left(x^{*}\right)\right\|\left\|F\left(x^{k}\right)-F\left(x^{k+1}\right)\right\| \\
& \geq\left\|F\left(x^{k}\right)-F\left(x^{k+1}\right)\right\|^{2}+2 \rho \mu\left\|G\left(x^{k}\right)-G\left(x^{*}\right)\right\|^{2} \\
& -2 \rho \mu\left\|G\left(x^{k}\right)-G\left(x^{*}\right)\right\|^{2}-\frac{\rho}{2 \mu}\left\|F\left(x^{k}\right)-F\left(x^{k+1}\right)\right\|^{2} \\
& \geq\left\|F\left(x^{k}\right)-F\left(x^{k+1}\right)\right\|^{2}-\frac{\rho}{2 \mu}\left\|F\left(x^{k}\right)-F\left(x^{k+1}\right)\right\|^{2} . \\
& =\left(1-\frac{\rho}{2 \mu}\right)\left\|F\left(x^{k}\right)-F\left(x^{k+1}\right)\right\|^{2} .
\end{aligned}
$$

Since (2) can be equivalently reformulated as the following variational inequalities

$$
\begin{aligned}
& \left\langle 2\left(F\left(x^{k+1}\right)-F\left(x^{k}\right)\right), F(x)-F\left(x^{k+1}\right)\right\rangle \\
& +2 \rho\left\langle G\left(x^{k}\right), F(x)-F\left(x^{k+1}\right)\right\rangle \geq 0, \\
& \quad \forall F(x) \in \Omega,
\end{aligned}
$$

let $F(x)=F\left(x^{*}\right)$ in (5), we have that the first inequality holds. Let $y=x^{*}\left(x^{*} \in X^{*}\right)$ in (4), and

$$
\left\langle G\left(x^{*}\right), F\left(x^{k}\right)-F\left(x^{*}\right)\right\rangle \geq 0,
$$

Combining this with Definition 2.1, we get

$$
\left\langle G\left(x^{k}\right), F\left(x^{k}\right)-F\left(x^{*}\right)\right\rangle \geq \mu\left\|G\left(x^{k}\right)-G\left(x^{*}\right)\right\|^{2},
$$

by (6), we have that the second inequality holds. The third inequality is based on Cauchy-Schwarz inequality. By $0<\rho<2 \mu$, we have $\Psi(k, k+1)>0$, the nonnegative sequence $\left\{H\left(x^{k}\right)\right\}$ is strictly decreasing.

Combining the definition of $H(x)$, we have

$$
\begin{aligned}
H\left(x^{k}\right) & =\left\|F\left(x^{k}\right)-F\left(x^{*}\right)\right\|^{2} \\
& +G\left(x^{*}\right)^{\cdot}\left(F\left(x^{k}\right)-F\left(x^{*}\right)\right) \\
& \geq\left\|F\left(x^{k}\right)-F\left(x^{*}\right)\right\|^{2} \geq 0 .
\end{aligned}
$$

So $\left\{H\left(x^{k}\right)\right\}$ converges, and we get $\Psi(k, k+1) \rightarrow 0$ as $k \rightarrow \infty$, and

$$
\lim _{k \rightarrow \infty}\left\|F\left(x^{k}\right)-F\left(x^{k+1}\right)\right\|=0 .
$$

Moreover, $\left\{H\left(x^{k}\right)\right\}$ is bounded since it is convergent, and so is $\left\{F\left(x^{k}\right)\right\}$ according to (7). Let $\left\{F\left(x^{k_{i}}\right)\right\}$ be a subsequence of $\left\{F\left(x^{k}\right)\right\}$ and converges toward $F(\bar{x})$, by (5), we obtain

$$
\langle G(\bar{x}), F(x)-F(\bar{x})\rangle \geq 0, \forall F(x) \in \Omega,
$$

by (9), we have $\bar{x}$ is a solution of (1). The $\bar{x}$ can be used as $x^{*}$ to define the function $H(x)$ : denoted $\bar{H}(x)$, we have

$$
\begin{aligned}
& \quad \| F(x)-F\left(\bar{x} \|^{2} \leq \bar{H}(x)\right. \\
& \leq \| F(x)-F\left(\bar{x} \|^{2}\right. \\
& +\|G(\bar{x})\|\|F(x)-F(\bar{x})\| .
\end{aligned}
$$

and we know that $\left\{\bar{H}\left(x^{k}\right)\right\}$ also converges, Substituting $F(x)$ in (10) with $F\left(x^{k_{i}}\right)$, we get $\bar{H}\left(x^{k_{i}}\right) \rightarrow 0$ as $i \rightarrow \infty$ . Thus, we have $\left\{\bar{H}\left(x^{k}\right)\right\} \rightarrow 0$ as $k \rightarrow \infty$. By using (7) again, we know that the sequence $\left\{F\left(x^{k}\right)\right\}$ converges globally toward $F(\bar{x})$. Since $F$ is onto $\Omega$, we have

$$
\begin{aligned}
& \left\|x^{k}-\bar{x}\right\| \\
& =\left\|M^{+}\left(F\left(x^{k+1}\right)-p\right)-M^{+}(F(\bar{x})-p)\right\| \\
& \leq\left\|M^{+}\right\|\left\|F\left(x^{k}\right)-F(\bar{x})\right\| \rightarrow 0(k \rightarrow \infty) .
\end{aligned}
$$

Then the desired result is followed.

\section{CONCLUSION AND PROSPECT}

In this paper, we present an auxiliary problem method for solving GVIP, and we also have showed that method has a global convergence, and we needn't the conditions which the mapping $G$ is continuously differentiable and monotone on $R^{n}$, and the conditions which the mapping $G$ is Lipschitz continuous is also moved, it is a new result for GVIP. It is uncertain whether the algorithm is global and $R$-linear convergence, this is a topic for further research.

\section{ACKNOWLEDGMENT}

The authors wish to give their sincere thanks to the editor and the anonymous referees for their valuable suggestions and helpful comments which improved the presentation of the paper. 
This work was supported by the Natural Science Foundation of China (Grant No. 11171180, 11101303), and Specialized Research Fund for the doctoral Program of Chinese Higher Education(20113705110002), and Shandong Provincial Natural Science Foundation (ZR2010AL005, ZR2011FL017), and the projects for reformation of Chinese universities logistics teaching and research (JZW2012065).

\section{REFERENCES}

[1] H. Stadtler and C. Kilger, Supply chain management and advanced planning, Springer-Verlag, Berlin, Germany, 2002.

[2] C. C. Poirier, Supply chain optimization: Building a total business network, Berrett-Kochler Publishers, San Francisco, California, 1996.

[3] C. C. Poirier, Advanced supply chain management: How to build a sustained competitive advantage, Berrett-Kochler Publishers, San Francisco, California, 1999

[4] F. Giannessi and A. Maugeri, Variational inequalities and network equilibrium problems, Plenum Press, New York, NY, 1955.

[5] A. Nagurney, J. Dong, and D. Zhang, "A supply chain network equilibrium model”, Transportation Research E, 38, pp. 281-303, 2002.

[6] J. Dong, D. Zhang, A. Nagurney, "A supply chain network equilibrium model with random demands", European Journal of Operational Research, 156, pp.194-212, 2004.

[7] A. Nagurney, J. Cruz, J. Dong and D. Zhang, "Supply chain networks, electronic commerce, and supply side and demand side risk", European Journal of Operational Research, 164, pp.120-142, 2005.
[8] M. A. Noor, "General variational inequalities", Applied Mathematics Letters, Vol.1, pp.119-121, 1988.

[9] F. Facchinei and J. S. Pang, Finite-Dimensional variational inequality and complementarity problems. New York: Springer, 2003.

[10] B.S. He, "A class of projection and contraction method for monotone variational inequalities", Appl. Math. Optim., 35, pp.69-76, 1997.

[11] M.V. Solodov and B.F. Svaiter, "A new projection method for variational inequality problems", SIAM J. Control Optim., 37, pp.765776, 1999.

[12] Y.J. Wang, N.H. Xiu and C.Y. Wang, "A new version of extragradient method for variational inequality problems", Comput. Math. Appl., 42, pp.969-979, 2001.

[13] Y.J. Wang, N.H. Xiu and C.Y. Wang, "Unified framework of extragradient-type methods for pseudomonotone variational inequalities", J. Optim. Theroy Appl., 111, pp. 641-656, 2001.

[14] Y.J. Wang, N.H. Xiu and J.Z. Zhang, "Modified extragradient methods for varitional inequalities and verification of solution existence", J. Optim. Theroy Appl., 119,pp.167-183, 2003.

[15] Y.J. Wang, "A new projection and contraction method for variational inequalities", Pure Math. and Appl., 13(4), pp.483-493, 2002.

[16] E.H. Zarantonello, Projections on convex sets in Hilbert Space and spectral theory, contributions to nonlinear functional analysis, New York: Academic Press, 1971.

[17] Roger A. Horn, Charles R. Johnson, Topics in matrix analysis, Cambridge. Univ. Press, 1991.

[18] N. El Farouq, "Convergent algorithm based on progressive regularization for solving pseudo-monotone variational inequalities", $\mathrm{J}$. Optimization Theory and Applications, 120, pp.455-485, 2004. 